\title{
Androgen Regulates Synaptic Input to Motoneurons of the Adult Rat Spinal Cord
}

\author{
Akira Matsumoto, ${ }^{1,2}$ Paul E Micevych, ${ }^{1}$ and Arthur P. Arnold ${ }^{2}$ \\ Departments of ${ }^{1}$ Anatomy and ${ }^{2}$ Psychology, and Laboratory of Neuroendocrinology, Brain Research Institute, University of \\ California, Los Angeles, California 90024
}

\begin{abstract}
Adult male rats (Sprague-Dawley) were castrated and implanted subcutaneously with Silastic capsules containing testosterone or nothing. Sham-castrated males served as controls. Four weeks following castration, cholera toxinhorseradish peroxidase (CT-HRP) was injected bilaterally into the bulbocavernosus muscles and animals were sacrificed $2 \mathrm{~d}$ later. The spinal cords containing the spinal nucleus of the bulbocavernosus (SNB) were dissected, processed with a modified tetramethylbenzidine (TMB) method for visualization of retrogradely transported CT-HRP, and examined at the ultrastructural level. Neuronal structures apposing the membranes of 150 TMB-labeled SNB neurons were analyzed by measuring the percentage of somatic and proximal dendritic membranes covered by synaptic contacts, synaptoid contacts, and neuron-neuron contacts. Most of the neuronal structures in the control and experimental SNB motoneurons consisted of synaptic contacts. The mean percentage of somatic and proximal dendritic membranes covered by synapses 4 weeks after castration was reduced to approximately $30 \%$ of those in control animals. However, treatment with testosterone for 4 weeks after castration prevented this decline. Castration and testosterone treatment also influenced the size and number of synaptic contacts per unit length of somatic and proximal dendritic membranes, and the incidence of neuron-neuron contacts and double synapses onto SNB motoneurons. These results indicate that androgen is critical for maintaining the organization of synaptic inputs to these spinal motoneurons in adult male rats.
\end{abstract}

Gonadal steroid hormones are considered to have organizational and activational effects on the sex steroid-accumulating neurons in the CNS (Arnold and Breedlove, 1985). Sex steroids play a significant role in modulating neuronal development and neuronal circuit formation during early developmental periods (Goy and McEwen, 1980; MacLusky and Naftolin, 1981; Arnold and Gorski, 1984; Breedlove, 1984; Toran-Allerand, 1984; Arai et al., 1986). These organizational actions of sex steroids can induce permanent sexual dimorphisms in nuclear volume (Gor-

\footnotetext{
Received July 8, 1987; revised Feb. 18, 1988; accepted Feb. 22, 1988.

We wish to thank Jean Lee and Toni Alexander for their excellent technical assistance and Cynthia Jordan for assistance with statistical analysis. Thanks are also due to Dr. Guido Zampighi for use of laboratory facilities in Jerry Lewis Neuromuscular Research Center, UCLA. This study was supported by NIH Grants NS23468 and HD15021.

Correspondence should be addressed to Dr. Arthur P. Arnold, Department of Psychology, University of California, 405 Hilgard Avenue, Los Angeles, CA 900241563.

Copyright (C) 1988 Society for Neuroscience $0270-6474 / 88 / 114168-09 \$ 02.00 / 0$
}

ski et al., 1978; Matsumoto and Arai, 1983), in neuronal number (Breedlove and Arnold, 1983a), in dendritic morphology (Greenough et al., 1977), and in synaptic organization (Raisman and Field, 1973; Matsumoto and Arai, 1980, 1986) in certain brain regions. In contrast, activational effects of sex steroids on adult brain are thought to be impermanent and reversible. Recent evidence suggests that even impermanent effects of gonadal steroids can involve major structural alterations in neural circuits. For example, DeVoogd and Nottebohm (1981; see also DeVoogd et al., 1985) have demonstrated that androgen induces dramatic growth of dendrites in the song control system of adult female canaries, correlated with androgenic activation of song in females. A similar androgenic regulation of dendritic length is observed in motoneurons in adult rodent spinal cord (Kurz et al., 1986; Forger and Breedlove, 1987). The present report examines the effect of androgen on synaptic input to these androgen-sensitive motoneurons in the rat.

The spinal nucleus of the bulbocavernosus (SNB) is a cluster of motoneurons located in the fifth and sixth lumbar segments of the spinal cords in male rats (Breedlove and Arnold, 1980; Schroder, 1980; McKenna and Nadelhaft, 1986). These motoneurons and their target muscles, the muscles bulbocavernosus and levator ani that attach to the penis, have an important role in copulatory behavior (Sachs, 1982; Hart and Melese-D'Hospital, 1983), which is sensitive to alterations in circulating levels of androgen in adulthood (Hart, 1983). Both the motoneurons (Breedlove and Arnold, 1980, 1983b) and muscles (Dube et al., 1976) accumulate or bind androgen. After castration, both somatic size (Breedlove and Arnold, 1981) and dendritic length (Kurz et al., 1986; Forger and Breedlove, 1987) of these motoneurons are significantly reduced, whereas androgen treatment of castrates increases somatic size and dendritic length of SNB motoneurons. These data suggest that the adult SNB retains a great deal of plasticity, which is expressed when androgen levels fluctuate. The androgenic regulation of somatic and dendritic membranes of the SNB motoneurons implies that the synaptic input to the SNB motoneurons is concomitantly altered. In the present study, as one step to elucidate how androgen regulates synaptic inputs to the SNB motoneurons, we performed quantitative electron microscopic analysis on SNB motoneurons in castrated adult male rats with or without testosterone treatment.

\section{Materials and Methods}

Fifteen adult male Sprague-Dawley rats were used, 5 per group. Male rats were castrated and implanted subcutaneously with Silastic capsules (\#602-285, $3.18 \mathrm{~mm}$ in outer diameter, $1.57 \mathrm{~mm}$ in inner diameter, 4.5 $\mathrm{cm}$ in length; Dow Corning, MI) containing testosterone (Steraloids) or nothing. Sham-castrated animals served as controls. Four weeks after 


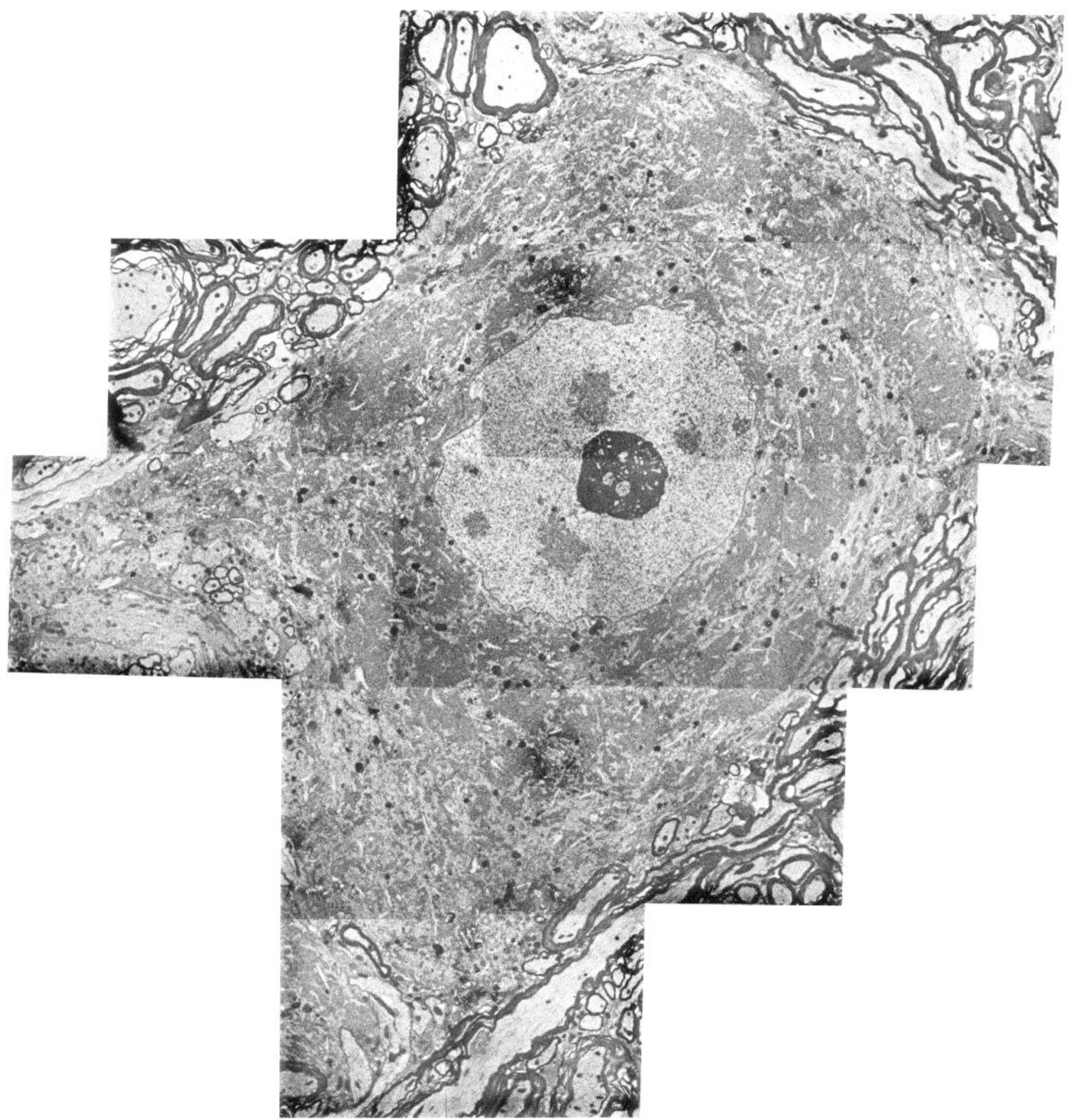

Figure 1. Photomontage of an SNB motoneuron in a testosterone-treated male rat 4 weeks after castration. $\times 2470$.

castration, $0.2 \%$ cholera toxin-horseradish peroxidase (CT-HRP; List Biological, Campbell, CA) was injected bilaterally into the bulbocavernosus muscles $(1 \mu \mathrm{l} /$ side) underr Nembutal anesthesia. Two days after CT-HRP injection, all animals were anesthetized with Nembutal and perfused transcardially with $200 \mathrm{ml} 0.9 \% \mathrm{NaCl}$ and subsequently with a mixture of $4 \%$ paraformaldehyde and $0.2 \%$ glutaraldehyde in 1000 $\mathrm{ml} 0.1 \mathrm{M}$ phosphate buffer (PB, $\mathrm{pH}$ 7.2). The body and seminal vesicle weights were recorded before and after autopsy, respectively. The lumbar portion of the spinal cord in each animal was removed, placed in the same fixative for $5 \mathrm{hr}$ and rinsed in $0.1 \mathrm{M} \mathrm{PB}$ for $24 \mathrm{hr}$ at $4^{\circ} \mathrm{C}$. The spinal cords were cut transversely with a Vibratome (Lancer Instruments, St. Louis) into $50 \mu \mathrm{m}$ sections. After a short rinse in $0.1 \mathrm{M}$ PB ( $\mathrm{pH}$ 6.5), the sections were processed according to a modification of the tetramethylbenzidine method (Mesulam, 1978; Lemann et al., 1985; Foerster, 1986). Preincubation of sections for $20 \mathrm{~min}$ at room temperature in a solution of $0.005 \% 3,3^{\prime}, 5,5^{\prime}$-tetramethylbenzidine (TMB; Sig$\mathrm{ma}), 0.1 \%$ sodium nitroferricyanide, $0.08 \%$ ammonium chloride, and $2 \%$ beta-D-glucose in $100 \mathrm{ml} 0.1 \mathrm{M} \mathrm{PB} \mathrm{(pH} \mathrm{6.5)} \mathrm{was} \mathrm{followed} \mathrm{by} \mathrm{in-}$ cubation for $20 \mathrm{~min}$ at room temperature with addition of 50 units of glucose oxidase. Thereafter, the sections were incubated for $15 \mathrm{~min}$ at 


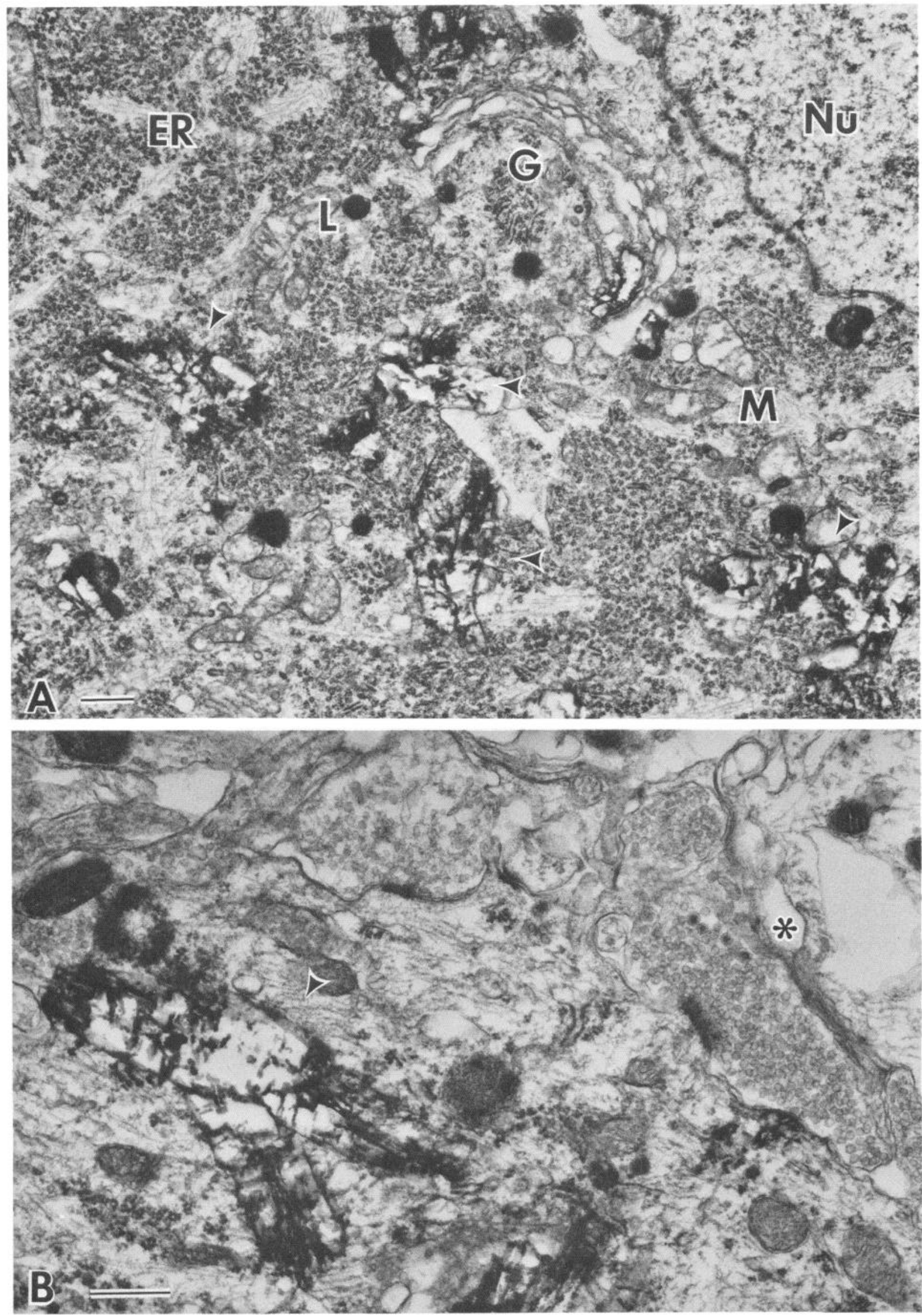


room temperature in a solution of $0.1 \% 3,3^{\prime}$-diaminobenzidine (DAB; Sigma), $0.08 \%$ ammonium chloride, $0.02 \%$ cobalt chloride, and $2 \%$ beta-D-glucose in $100 \mathrm{ml} 0.1 \mathrm{M} \mathrm{PB} \mathrm{(pH} \mathrm{7.2),} \mathrm{and} \mathrm{subsequently} \mathrm{incubated}$ for $15 \mathrm{~min}$ at room temperature with addition of 50 units of glucose oxidase. The DAB step served to make the reaction product insoluble so that it could be viewed after processing for electron microscopy. After a short rinse in $0.1 \mathrm{M} \mathrm{PB}$, the sections were postfixed in $1 \% \mathrm{OsO}_{4}$ in $0.15 \mathrm{~m}$ cacodylate buffer ( $\mathrm{pH} 7.2)$ for $1 \mathrm{hr}$ at room temperature. After staining with $1 \%$ uranyl acetate for $30 \mathrm{~min}$, the sections were dehydrated in graded ethanols and embedded in epoxy resin. Thick sections of the spinal cords were stained with toluidine blue to identify the existence of the TMB reaction product in the cytoplasm of the SNB motoneurons. Adjacent ultrathin sections were stained with lead citrate and examined under a Zeiss E109 electron microscope.

Ten labeled motoneurons with visible nuclei were randomly selected in each spinal cord (150 total in all groups). Using photomontages of these motoneurons at a final magnification of $8590 \times$, we analyzed the amount of synaptic afferent contact onto the somatic and proximal dendritic membranes. Neuronal contacts were classified into 3 types. (1) The contact of an axon terminal containing synaptic vesicles which possessed thickening of the pre- and postsynaptic membranes was classified as a synaptic contact (Figs. $3 A, 4$ ). (2) The contact of an axon terminal without membrane specialization was classified as a synaptoid contact (Figs. 3B, 4). (3) The direct apposition between a soma and an adjacent soma, between a soma and an adjacent dendrite, or between a proximal dendrite and an adjacent dendrite was classified as a neuronneuron contact (Fig. 3C). Each neuron-neuron apposition included lengths of membrane specialization reminiscent of desmosomes, i.e., symmetrical accumulation of electron-dense material in the cytoplasm along both membranes.

Occasionally axons made synaptic contact with an SNB soma (or dendrite), as well as another soma or dendrite in the same section (Fig. $3 D$ ). The frequency of such double synapses was also compared in the 3 groups.

The border between somatic and dendritic membranes was defined as the point where the spherical shape of the somatic membrane was broken by the origin of a dendrite. If this site was unclear, the boundary between soma and proximal dendrite was defined as the position where the width of the proximal dendrite corresponded to the minor diameter of the nucleus. We examined only dendrites that were near the soma, usually no more than one somatic diameter from the cell body itself. The perimeters of somata and proximal dendrites and the covering lengths of synaptic contacts, synaptoid contacts, and neuron-neuron contacts were measured with a tablet digitizer connected with a computer. The percentage covering of neuronal contacts (total length of neuronal contacts/perimeter of soma or proximal dendrites), the frequency of neuronal contacts (number of neuronal contacts $/ \mu \mathrm{m}$ of membrane of soma or proximal dendrites), and the size of neuronal contacts (total length of neuronal contacts/number of neuronal contacts) were calculated for each type of neuronal contact. To analyze differences between groups, a 1-way analysis of variance was performed for each parameter measured, with $n$ the number of animals in each group. If there was a significant main effect of treatment, post hoc tests were also run to confirm the differences between specific groups.

\section{Results}

The weight of seminal vesicles in castrates $(0.198 \pm 0.030 \mathrm{gm}$, mean \pm SEM) was significantly smaller than that in control rats $(2.098 \pm 0.163 ; p<0.0001)$. The weight of seminal vesicles in castrates given testosterone for 4 weeks $(2.445 \pm 0.112)$ was significantly greater than that in castrates $(p<0.0001)$ and was comparable to the control value. There were no significant differences in body weight among the 3 groups (controls, $487.2 \pm$
Table 1. Effect of testosterone on length (mean $\perp$ SEM) of the perimeter of somata of the SNB motoneurons in control and experimental animals

\begin{tabular}{lll} 
Group & $\begin{array}{l}\text { Number of } \\
\text { rats }\end{array}$ & $\begin{array}{l}\text { Perimeter } \\
(\mu \mathrm{m})\end{array}$ \\
\hline Controls & 5 & $155.1 \pm 4.9$ \\
Castrates & 5 & $114.8+2.0^{a}$ \\
Castrates + testosterone & 5 & $147.2 \pm 2.9$
\end{tabular}

${ }^{a}$ Comparison with controls: $p<0.0001$.

$15.3 \mathrm{gm}$; castrates, $445.6 \pm 18.1$; castrates given testosterone, $464.8 \pm 12.3$ ).

The TMB method followed by DAB stabilization resulted in good preservation of both the reaction product and the ultrastructural integrity of the SNB motoneurons (Figs. 1, 2). The labeled SNB motoneurons contained a round nucleus with a prominent nucleolus (Fig. 1) and various cytoplasmic organelles, such as rough endoplasmic reticulum, mitochondria, Golgi apparatus, and lysosomes (Fig. $2 A$ ). The reaction product complex consisted of several aggregated lucent spaces covered with amorphous or threadlike electron-dense material present in the cytoplasm of cell bodies and proximal dendrites (Fig. 2). Although myelinated fibers were observed in the proximity of motoneurons, the neuropil immediately adjacent to these motoneurons was fully occupied by unmyelinated axons, dendrites, and glial processes (Fig. 1). Neuronal endings contacting somata or proximal dendrites contained a number of synaptic vesicles (about $50 \mathrm{~nm}$ in diameter) and mitochondria (Fig. 3A). Occasionally, a small number of large granular vesicles (about $100 \mathrm{~nm}$ in diameter) were found to coexist with synaptic vesicles in the axon terminals (Fig. 2B). Most of the neuronal contacts on somatic and dendritic membranes consisted of synaptic contacts (Figs. 3A, 4; Tables 2, 3), whereas the incidence of synaptoid contacts was very low (Figs. $3 B$, 4; Tables 2,3 ). The neuronneuron contacts, characterized by desmosome-like structures, were occasionally observed between somata, between somata and dendrites, or between proximal dendrites and other dendrites (Fig. 3C; Tables 2, 3).

Castration reduced both the perimeter of somata and the synaptic covering of SNB motoneurons, and androgen treatment prevented these changes (Tables 1,2 ). There was a statistically significant main effect of treatment for the following measures $[F \mathrm{~s}(2,12)>9.2, p<0.004]$ : somatic perimeter, percentage covering of synaptic contacts on both somata and dendrites, percentage covering of neuron-neuron contacts on somata, size and frequency of synaptic contacts on both somata and dendrites, frequency of neuron-neuron contacts on somata, and frequency of double synapses on both somata and dendrites (Tables 3-5). In each case, post hoc tests revealed that all of the indices of synaptic covering, frequency, and size were lower in castrates than in controls $(p<0.02)$ and that 4 weeks of tes-

Figure 2. $A$, Cell body of an SNB motoneuron in a testosterone-treated male rat 4 weeks after castration. Rough endoplasmic reticulum (ER) is well developed, and mitochondria $(M)$, the Golgi apparatus $(G)$, and lysosomes $(L)$ are prominent. TMB-DAB reaction product $(a r r o w h e a d)$ can be seen in the cytoplasm. $N u$, nucleus. Scale bar, $0.5 \mu \mathrm{m} . \times 17,700 . B$, Proximal dendrite of an SNB motoneuron in a testosterone-treated male rat 4 weeks after castration. TMB-DAB reaction product (arrowhead) is found in the cytoplasm. Two axon terminals make contact with the proximal dendrite. One terminal (*) contains a few large granular vesicles together with hollow synaptic vesicles. Scale bar, $0.5 \mu \mathrm{m}$. $\times 28,800$. 

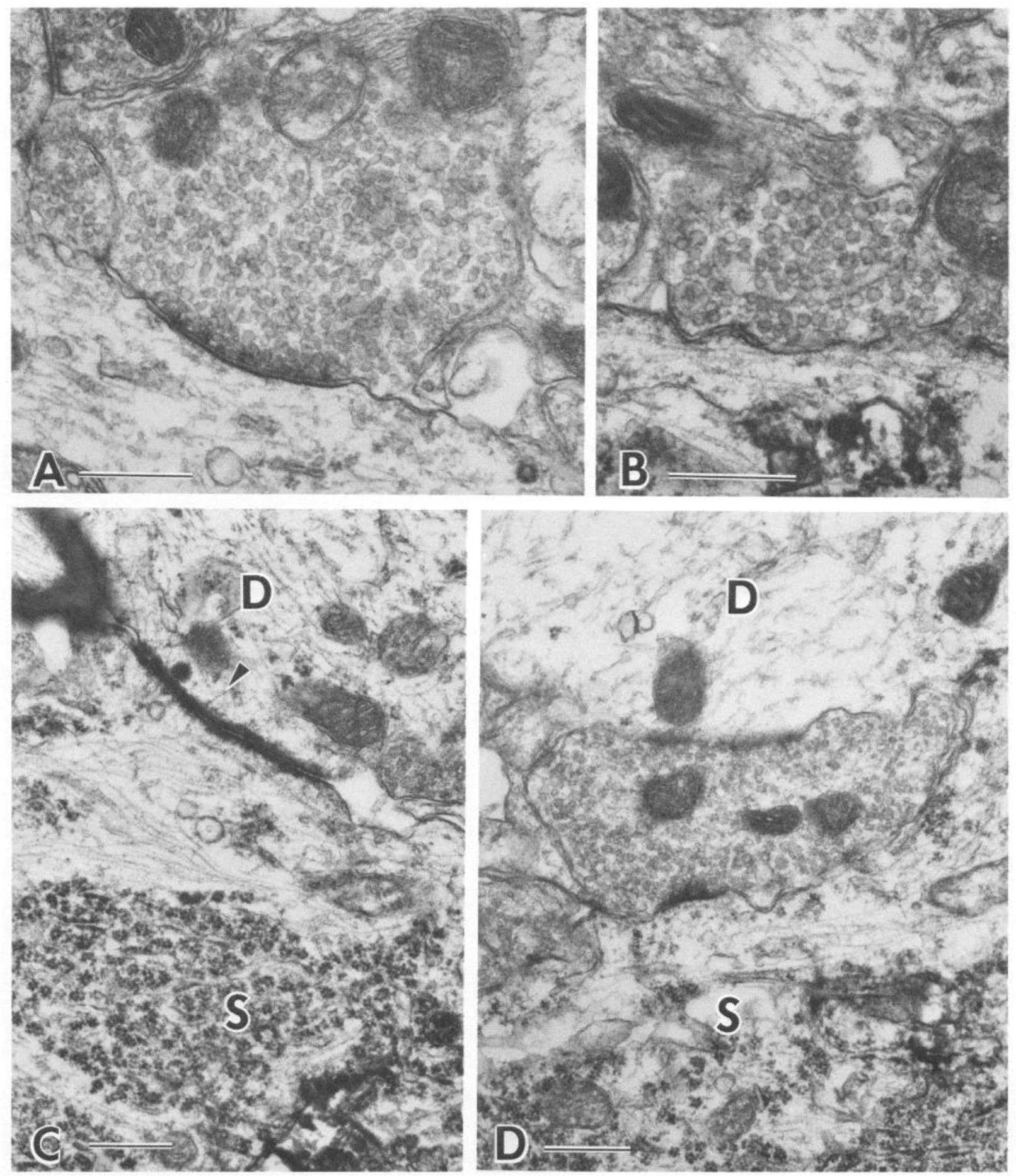

Figure 3. A, Synaptic contact onto an SNB motoneuron in a testosterone-treated male rat 4 weeks after castration. Scale bar, $0.5 \mu \mathrm{m}$. $\times 35,500$. $B$, Synaptoid contact onto an SNB motoneuron in a testosterone-treated male rat 4 weeks after castration. Note the absence of membrane thickening required for identification as a true synapse. Scale bar, $0.5 \mu \mathrm{m} . \times 40,900$. $C$, Unidentified dendrite $(D)$ makes a neuron-neuron contact onto an SNB motoneuron soma $(S)$ by means of a desmosome-like structure (arrowhead) in a testosterone-treated male rat 4 weeks after castration. It is possible that the dendrite $(D)$ is from an ipsilateral or contralateral SNB motoneuron, since SNB dendrites are known to appose other SNB somata and dendrites (Rose and Collins, 1985). Scale bar, $0.5 \mu \mathrm{m} . \times 27,000 . D$, Axon makes a double synapse onto an SNB motoneuronal soma $(S)$ and an unidentified dendrite $(D)$ in a testosterone-treated male rat 4 weeks after castration. Scale bar, $0.5 \mu \mathrm{m} . \times 27,000$.

tosterone treatment prevented this decline (i.e., no significant difference between testosterone-treated castrates and controls, $p>0.05$ ). There were no significant differences in the mean percentage covering, frequency, and size of synaptoid contacts on somatic and proximal dendrites among the 3 groups. Similarly, there were no significant differences in the mean percentage covering, frequency, and size of neuron-neuron contacts on proximal dendrites among the three groups. 
Table 2. Percentage (mean \pm SEM) of somatic and dendritic membranes covered by three types of neuronal contacts onto SNB motoncurons in control and experimental animals

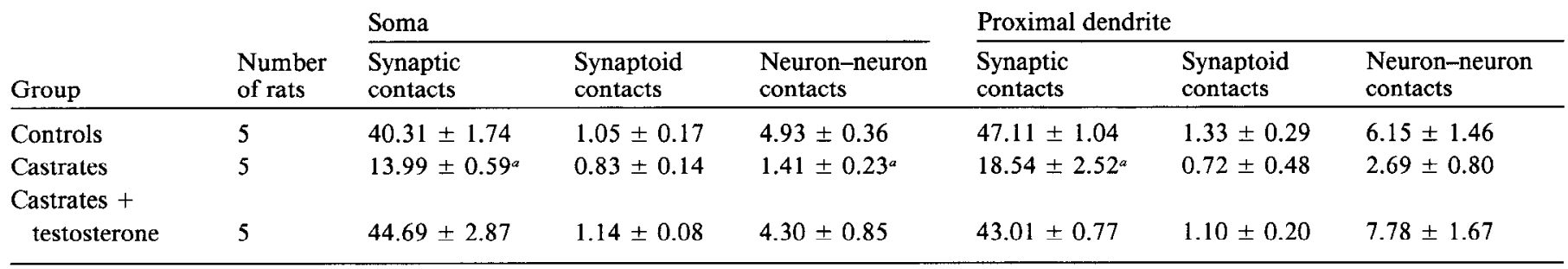

a Comparison with controls: $p<0.001$.

\section{Discussion}

Our results indicate that there is a great deal of plasticity in the organization of synaptic input to SNB motoneurons in adult rats. Castration dramatically reduced the percentage of the somatic and proximal dendritic membrane covered by synapses and other contacts, and this change was prevented by testosterone treatment beginning on the day of castration. In castrates, the percentage of membrane covered by synapses was only about $1 / 3$ of that found in intact males. Testosterone-treated castrates were no different from controls. These results are similar to those described independently by Leedy et al. (1987). Castration has previously been reported to decrease the size of SNB somata and the length of SNB dendrites (Breedlove and Arnold, 1981; Kurz et al., 1986; Forger and Breedlove, 1987). Since the absolute amount of somatic and dendritic membrane is greatly reduced by castration, our finding of a decrease in percentage of membrane covered by synapses indicates that the loss of synapses is proportionally greater than the reduction in somatic membrane area. There can be little doubt that these changes in the synaptic input to the SNB motoneurons, and changes in the morphology of the motoneurons themselves, must result in important changes in the function of the SNB system. The present results indicate that spinal motoneurons can retain a great deal of morphological and synaptic plasticity into adult life. Because androgen levels in rodents fluctuate with the seasons (Forger and Breedlove, 1987), stress, and aging (Ghanadian et al., 1975; Peng et al., 1983), the synaptic changes induced by castration may reflect an ongoing process of synaptic organization and reorganization regulated by androgen throughout the adult life of the rat. The role of the SNB motoneurons in copulation (Sachs, 1982; Hart and Melese-d'Hospital, 1983), and the role of androgen in stimulating copulation, suggest that androgen's effects on synaptic input to SNB motoneurons are an important part of androgenic control of copulation itself.
Our results suggest that castration reduces both the size and number of synaptic contacts onto SNB motoneurons. For example, the frequency of somatic synaptic contacts in castrates was $42 \%$ of intact rats, and the mean size of such synaptic contacts was $82 \%$ of intact values. Because smaller synapses would appear to occur less frequently simply because they occur in fewer sections, it becomes important to ask whether the reduction in synapse size accounts for the observed reduction in frequency of synapses. Given that the section thickness (approximately $90 \mathrm{~nm}$ ) was small relative to the size of synapses, the frequency of finding synapses should have been linearly proportional to their size. Thus, synapses in castrates would be expected to be observed $82 \%$ as frequently as those in intacts, based on their size alone. Because the observed frequency is about one-half this expected value (42\%), our data indicate that the reduction in frequency is greater than predicted from the reduction in synapse size and that castration reduces both the number and size of synaptic contacts.

Because we used an arbitrary method for drawing the line between somatic and dendritic membranes, it is conceivable that shrinkage of the soma, caused by castration, would move the boundary between soma and dendrite. Thus, the most proximal dendritic membrane in intact males might be analyzed as the most distal somatic membrane of castrates. Such an error is likely to be small, and in any case would not change the results, since castration reduced synaptic contacts on both types of membrane.

There is a variety of evidence showing that sex steroids induce morphological changes in the adult CNS. Treatment with androgen has been reported to result in changes in the volumes of song control regions of the canary striatum (Nottebohm, 1980) and a portion of the preoptic area of the Mongolian gerbil (Commins and Yahr, 1984). Androgen treatment also changes dendritic morphology in the canary brain (DeVoogd and Nottebohm, 1981) and rodent spinal cord (Kurz et al., 1986; Forger

Table 3. Effect of testosterone on frequency (mean \pm SEM) of neuronal contacts per micron of somatic and proximal dendritic membranes of the SNB motoneurons in control and experimental animals

\begin{tabular}{|c|c|c|c|c|c|c|c|}
\hline \multirow[b]{2}{*}{ Group } & \multirow[b]{2}{*}{$\begin{array}{l}\text { Number } \\
\text { of rats }\end{array}$} & \multicolumn{3}{|l|}{ Soma } & \multicolumn{3}{|c|}{ Proximal dendrite } \\
\hline & & $\begin{array}{l}\text { Synaptic } \\
\text { contacts }\end{array}$ & $\begin{array}{l}\text { Synaptoid } \\
\text { contacts }\end{array}$ & $\begin{array}{l}\text { Neuron-neuron } \\
\text { contacts }\end{array}$ & $\begin{array}{l}\text { Synaptic } \\
\text { contacts }\end{array}$ & $\begin{array}{l}\text { Synaptoid } \\
\text { contacts }\end{array}$ & $\begin{array}{l}\text { Neuron-neuron } \\
\text { contacts }\end{array}$ \\
\hline Controls & 5 & $0.229 \pm 0.012$ & $0.009 \pm 0.001$ & $0.028 \pm 0.003$ & $0.257 \pm 0.011$ & $0.021 \pm 0.008$ & $0.030 \pm 0.007$ \\
\hline $\begin{array}{l}\text { Castrates }+ \\
\text { testosterone }\end{array}$ & 5 & $0.251+0.014$ & $0.011+0.001$ & $0.025+0.003$ & $0.254 \pm 0.011$ & $0.011 \pm 0.002$ & $0.043 \pm 0.008$ \\
\hline
\end{tabular}


Figure 4. Proximal dendrite $(P D)$ of an SNB motoneuron labeled by TMB$\mathrm{DAB}$ reaction product (open arrow), illustrating synaptic contacts (arrowheads) and a synaptoid contact (solid arrow), from a testosterone-treated male rat 4 weeks after castration. Scale bar, $0.5 \mu \mathrm{m} . \times 8590$.

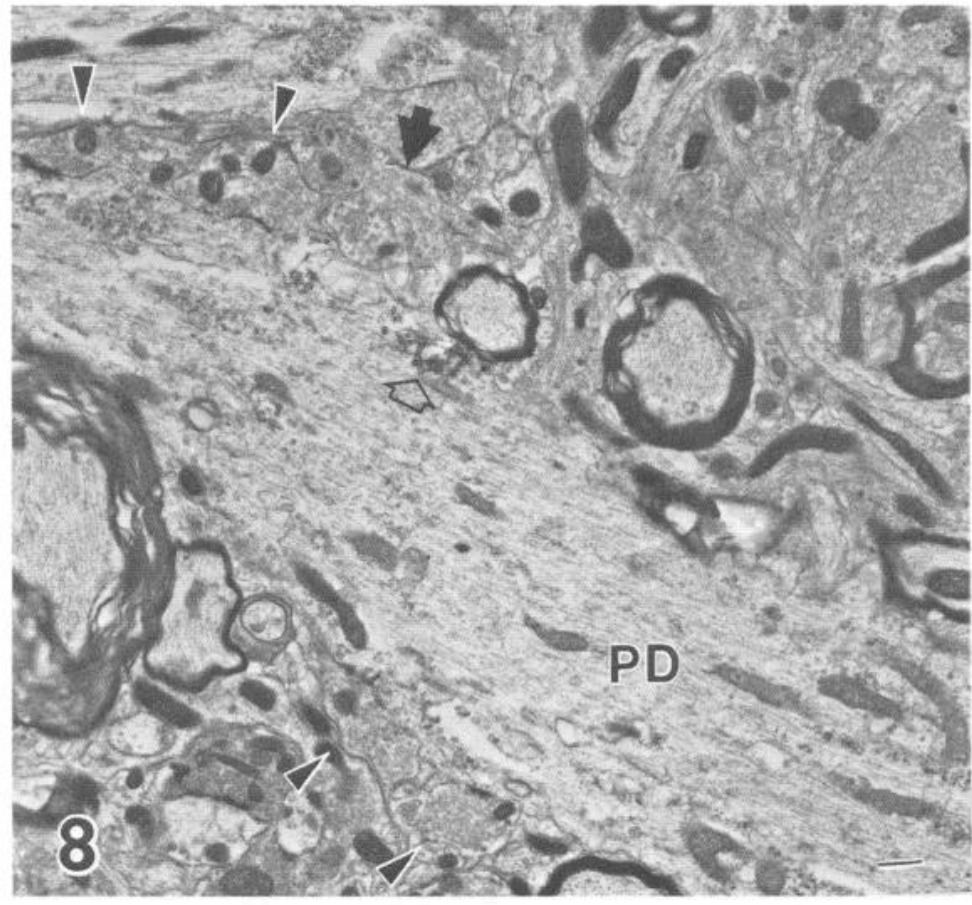

and Breedlove, 1987), and alters the number of synapses in portions of the canary striatum (DeVoogd et al., 1985). Estrogen has been shown to stimulate synaptogenesis in completely deafferented (Matsumoto and Arai, 1979, 1981, 1985) or intact hypothalamic arcuate nucleus (Garcia-Segura et al., 1986), and in the hypothalamic ventromedial nucleus (Carrer and Aoki, 1982) of ovariectomized female rats. All of these brain regions have been found to accumulate sex steroids (Stumpf, 1970; Pfaff and Keiner, 1973; Arnold et al., 1976; Breedlove and Arnold, 1980, 1983b; Commins and Yahr, 1985). This evidence indicates that brain regions containing sex-steroid-accumulating neurons in adult animals possess a considerable plasticity in response to sex steroids and that sex steroids have the potential to stimulate the growth of neuronal processes and remodel neural circuits in the adult brain. The results of the present study indicate that androgen substantially contributes to the reorganization of neural circuits of adult spinal cord. Kurz et al. (1986) found that androgen controls the dendritic length of the SNB motoneurons in adult rat spinal cord, and the present study confirmed an androgenic effect on the amount of somatic membrane (Breedlove and Arnold, 1981). Although the present results implicate androgen in the reorganization of synaptic inputs on the SNB motoneurons, it is uncertain whether androgen participates in the reoccupation of synaptic sites by the axon terminals which originally made synaptic contact or by the newly formed axon terminals while the original ones have degenerated after castration.

Previous studies have suggested which kinds of neurotransmitters may be contained in afferents to SNB motoneurons. Immunoreactive somatostatin fibers (Schroder, 1984) and catecholaminergic fibers (Schroder and Skagerberg, 1985) have been observed closely surrounding the somata of rat lumbosacral motoneurons. Furthermore, recent studies have suggested the presence of noradrenalin, serotonin, substance $\mathrm{P}$, and met-enkephalin in fibers and terminals in close proximity to SNB somata and dendrites (Kojima et al., 1985; Micevych et al., 1986). These data indicate that the terminals of these fibers may make synaptic contact with SNB neurons. In fact, serotoninergic (Aghajanian and McCall, 1980; Vacca et al., 1982; Takeuchi et al., 1983) and substance P axon terminals (Barber et al., 1979) are known to make synaptic connection with lumbar and other motoneurons. In the present study, it has been clearly established that synaptic inputs to the SNB motoneurons can be regulated by androgenic influence. Further studies are needed to determine the chemical identity of neuronal inputs to the SNB motoneurons which are affected by androgen.

Table 4. Effect of testosterone on size ( $\mu \mathrm{m}$, mean \pm SEM) of neuronal contacts on somatic and proximal dendritic membranes of the SNB motoneurons in control and experimental animals

\begin{tabular}{|c|c|c|c|c|c|c|c|}
\hline \multirow[b]{2}{*}{ Group } & \multirow[b]{2}{*}{$\begin{array}{l}\text { Number } \\
\text { of rats }\end{array}$} & \multicolumn{3}{|l|}{ Soma } & \multicolumn{3}{|c|}{ Proximal dendrite } \\
\hline & & $\begin{array}{l}\text { Synaptic } \\
\text { contacts }\end{array}$ & $\begin{array}{l}\text { Synaptoid } \\
\text { contacts }\end{array}$ & $\begin{array}{l}\text { Neuron-neuron } \\
\text { contacts }\end{array}$ & $\begin{array}{l}\text { Synaptic } \\
\text { contacts }\end{array}$ & $\begin{array}{l}\text { Synaptoid } \\
\text { contacts }\end{array}$ & $\begin{array}{l}\text { Neuron-neuron } \\
\text { contacts }\end{array}$ \\
\hline Controls & 5 & $1.74 \pm 0.02$ & $1.12 \pm 0.09$ & $2.06 \pm 0.42$ & $1.87 \pm 0.06$ & $1.23 \pm 0.13$ & $2.00 \pm 0.28$ \\
\hline Castrates & 5 & $1.40 \pm 0.04^{a}$ & $1.28 \pm 0.15$ & $1.20 \pm 0.19$ & $1.31 \pm 0.10^{a}$ & $0.75 \pm 0.22$ & $1.88 \pm 1.03$ \\
\hline $\begin{array}{l}\text { Castrates + } \\
\text { testosterone }\end{array}$ & 5 & $1.78 \pm 0.04$ & $1.08 \pm 0.03$ & $1.89 \pm 0.16$ & $1.69 \pm 0.04$ & $1.08 \pm 0.07$ & $1.92 \pm 0.30$ \\
\hline
\end{tabular}

a Comparison with controls: $p<0.001$. 
Table 5. Effect of testosterone on frequency (mean \pm SEM) of double synapses per micron of somatic and proximal dendritic membranes of the SNB motoneurons in control and experimental animals

\begin{tabular}{llll} 
Group & $\begin{array}{l}\text { Num- } \\
\text { ber of } \\
\text { rats }\end{array}$ & Soma & $\begin{array}{l}\text { Proximal } \\
\text { dendrite }\end{array}$ \\
\hline Controls & 5 & $0.016 \pm 0.003$ & $0.019 \pm 0.003$ \\
Castrates & 5 & $0.004 \pm 0.001^{a}$ & $0.008 \pm 0.002^{a}$ \\
$\begin{array}{l}\text { Castrates }+ \\
\quad \text { testosterone }\end{array}$ & 5 & $0.021 \pm 0.003$ & $0.024 \pm 0.003$
\end{tabular}

${ }^{a}$ Comparison with controls: $p<0.02$.

\section{References}

Aghajanian, G. K., and R. B. McCall (1980) Serotonergic synaptic input to facial motoneurons: Localization by electron-microscopic autoradiography. Neuroscience 5: 2155-2162.

Arai, Y., A. Matsumoto, and M. Nishizuka (1986) Synaptogenesis and neuronal plasticity to gonadal steroids: Implications for the development of sexual dimorphism in the neuroendocrine brain. In Current Topics in Neuroendocrinology, Vol. 7, Morphology of Hypothalamus and Its Connections, D. Ganten and D. Pfaff, eds., pp. 291-307, Springer-Verlag, Berlin.

Arnold, A. P., and S. M. Breedlove (1985) Organizational and activational effects of sex steroids on brain and behavior: A reanalysis. Horm. Behav. 19: 469-498.

Arnold, A. P., and R. A. Gorski (1984) Gonadal steroid induction of structural sex differences in the central nervous system. Annu. Rev. Neurosci. 7: 413-442.

Arnold, A. P., F. Nottebohm, and D. W. Pfaff (1976) Hormone concentrating cells in vocal control and other areas of the brain of the zebra finch (Poephila guttata). J. Comp. Neurol. 165: 478-512.

Barber, R. P., J. E. Vaughn, J. R. Slemmon, P. M. Salvaterra, E. Roberts, and S. E. Leeman (1979) The origin, distribution and synaptic relationships of substance $P$ axons in rat spinal cord. J. Comp. Neurol. 184: $331-352$.

Breedlove, S. M. (1984) Stcroid influences on the development and function of a neuromuscular system. Prog. Brain Res. 61: 147-170.

Breedlove, S. M., and A. P. Arnold (1980) Hormone accumulation in a sexually dimorphic motor nucleus of the rat spinal cord. Science 210: 564-566.

Breedlove, S. M., and A. P. Arnold (1981) Sexually dimorphic motor nucleus in the rat lumbar spinal cord: Response to adult hormone manipulation, absence in androgen-insensitive rats. Brain Res. 225: 297-307.

Breedlove, S. M., and A. P. Arnold (1983a) Hormonal control of a developing neuromuscular system. II. Sensitive periods for the androgen-induced masculinization of the rat spinal nucleus of the bulbocavernosus. J. Neurosci. 3: 424-432.

Breedlove, S. M., and A. P. Arnold (1983b) Sex differences in the pattern of steroid accumulation by motoneurons of the rat lumbar spinal cord. J. Comp. Neurol. 215: 211-216.

Carrer, H. F., and A. Aoki (1982) Ultrastructural changes in the hypothalamic ventromedial nucleus of ovariectomized rats after estrogen treatment. Brain Res. 240: 221-233.

Commins, D., and P. Yahr (1984) Adult testosterone levels influence the morphology of a sexually dimorphic area in the mongolian gerbil brain. J. Comp. Neurol. 224: 132-140.

Commins, D., and P. Yahr (1985) Autoradiographic localization of estrogen and androgen receptors in the sexually dimorphic area and other regions of the gerbil brain. J. Comp. Neurol. 231: 473-489.

DeVoogd, T., and F. Nottebohm (1981) Gonadal hormones induce dendritic growth in the adult avian brain. Science 214: 202-204.

DeVoogd, T. J., B. Nixdorf, and F. Nottebohm (1985) Synaptogenesis and changes in synaptic morphology related to acquisition of a new behavior. Brain Res. 329: 304-308.

Dube, J. Y., R. Lesage, and R. R. Tremblay (1976) Androgen and estrogen binding in rat skeletal and perineal muscles. Can. J. Biochem. 54: $50-55$.
Foerster, A. (1986) Improved HRP detection in the light and electron microscopes. Soc. Neurosci. Abstr. 12: 1566.

Forger, N. G., and S. M. Breedlove (1987) Seasonal variation in mammalian striated muscle mass and motoneuron morphology. J. Neurobiol. 18: 155-165.

Garcia-Segura, L. M., D. Baetens, and F.. Naftolin (1986) Synaptic remodelling in arcuate nucleus after injection of estradiol valerate in adult female rats. Brain Res. 366: 131-136.

Ghanadian, R., I. G. Lewis, and G. D. Chisholm (1975) Serum testosterone and dihydrotestosterone changes with age in rat. Steroids 25: 753-762.

Gorski, R. A., J. H. Gordon, J. E. Shryne, and A. M. Southam (1978) Evidence for a morphological sex difference within the medial preoptic area of the rat brain. Brain Res. 148: 333-346.

Goy, R. W., and B. S. McEwen (1980) Sexual Differentiation of the Brain, MIT Press, Cambridge.

Greenough, W. T., C. S. Carter, C. Steerman, and T. J. DeVoogd (1977) Sex differences in dendritic patterns in hamster preoptic area. Brain Res. 126: 63-72.

Hart, B. L. (1983) Role of testosterone secretion and penile reflexes in sexual behavior and sperm competition in male rats: A theoretical contribution. Physiol. Behav. 31: 823-827.

Hart, B. L., and P. Y. Melese-D'Hospital (1983) Penile mechanisms and the role of the striated penile muscles in penile reflexes. Physiol. Behav. 31: 807-813.

Kojima, M., T. Matsuura, A. Tanaka, T. Amagi, J. Imanishi, and Y. Sano (1985) Characteristic distribution of noradrenergic terminals on the anterior horn motoneurons innervating the perineal striated muscles in the rat. An immuno-electronmicroscopic study. Anat. Embryol. 171: 267-273.

Kurz, E. M., D. R. Sengelaub, and A. P. Arnold (1986) Androgens regulate the dendritic length of mammalian motoneurons in adulthood. Science 232: 395-398.

Leedy, M. G., M. S. Beattie, and J. C. Bresnahan (1987) Testosterone induced plasticity of synaptic inputs to adult mammalian motoneuron. Brain Res. 424: 386-390.

Lemann, W., C. B. Saper, D. B. Rye, and B. H. Wainer (1985) Stabilization of TMB reaction product for electron microscopic retrograde and anterograde fiber tracing. Brain Res. Bull. 14: 277-281.

MacLusky, N. J., and F. Naftolin (1981) Sexual differentiation of the central nervous system. Science 211: 1294-1303.

Matsumoto, A., and Y. Arai (1979) Synaptogenic effect of estrogen on the hypothalamic arcuatc nucleus of the adult female rat. Cell Tissue Res. 198: 427-433.

Matsumoto, A., and Y. Arai (1980) Sexual dimorphism in 'wiring pattern' in the hypothalamic arcuate nucleus and its modification by neonatal hormonal environment. Brain Res. 190: 238-242.

Matsumoto, A., and Y. Arai (1981) Neuronal plasticity in the deafferented hypothalamic arcuate nucleus of adult female rats and its enhancement by treatment with estrogen. J. Comp. Neurol. 197: 197205.

Matsumoto, A., and Y. Arai (1983) Sex difference in volume of the ventromedial nucleus of the hypothalamus in the rat. Endocrinol. Jpn. 30: 277-280.

Matsumoto, A., and Y. Arai (1985) Estrogen stimulates neuronal plasticity in the deafferented hypothalamic arcuate nucleus in aged female rats. Neurosci. Res. 2: 412-418.

Matsumoto, A., and Y. Arai (1986) Male-female difference in synaptic organization of the ventromedial nucleus of the hypothalamus in the rat. Neuroendocrinology 42: 232-236.

McKenna, K. E., and I. Nadelhaft (1986) The organization of the pudendal nerve in the male and female rat. J. Comp. Neurol. 248: 532-549.

Mesulam, M.-M. (1978) Tetramethyl benzidine for horseradish peroxidase neurohistochemistry: A non-carcinogenic blue reaction-product with superior sensitivity for visualizing neural afferents and efferents. J. Histochem. Cytochem. 26: 106-117.

Micevych, P. E, A. Coquelin, and A. P. Arnold (1986) Immunohistochemical distribution of substance $P$, serotonin, and methionine enkephalin in sexually dimorphic nuclei of the rat lumbar spinal cord. J. Comp. Neurol. 248: 235-244.

Nottebohm, F. (1980) Testosterone triggers growth of brain vocal control nuclei in adult female canaries. Brain Res. 189: 429-436.

Peng, M. T., H. K. Hsu, W. P. Pi, K. M. Wu, C. F. Liao, and W. C.M. Wan (1983) Pattern of reproductive hormone secretion and dis- 
appearance rates of LH and FSH in senile male rats. Gerontology 29: $32-40$.

Pfaff, D. W., and M. Keiner (1973) Atlas of estradiol-concentrating cells in the central nervous system of the female rats. J. Comp. Neurol. 151: 121-158.

Raisman, G., and P. M. Field (1973) Sexual dimorphism in the neuropil of the preoptic area of the rat and its dependence on neonatal androgen. Brain Res. 54: 1-29.

Rose, R. D., and W. F. Collins III (1985) Crossing dendrites may be a substrate for synchronized activation of penile motoneurons. Brain Res. 337: 373-377.

Sachs, B. D. (1982) Role of striated penile muscles in penile reflexes, copulation, and induction of pregnancy in the rat. J. Reprod. Fertil. 66: 433-443.

Schroder, H. D. (1980) Organization of the motoneurons innervating the pelvic muscles of the male rat. J. Comp. Neurol. 192: 567-587.

Schroder, H. D. (1984) Somatostatin in the caudal spinal cord: An immunohistochemical study of the spinal centers involved in the innervation of pelvic organs. J. Comp. Neurol. 223: 400-414.

Schroder, H. D., and G. Skagerberg (1985) Catecholamine innervation of the caudal spinal cord in the rat. J. Comp. Neurol. 242: 358-368.

Stumpf, W. E. (1970) Estrogen-neurons and estrogen-neuron system in the periventricular brain. Am. J. Anat. 129: 207-218.

Takeuchi, Y., M. Kojima, T. Matsuura, and Y. Sano (1983) Serotonergic innervation on the motoneurons in the mammalian brainstem. Light and electron microscopic immunohistochemistry. Anat. Embryol. 167: 321-333.

Toran-Allerand, C. D. (1984) On the genesis of sexual differentiation of the central nervous system: Morphogenic consequences of steroid exposure and possible role of alpha-fetoprotein. Prog. Brain Res. 61: 63-98.

Vacca, L. L., J. Hobbs, S. Abrahams, and E. Naftchi (1982) Ultrastructural localization of substance $P$ immunoreactivity in the ventral horn of the rat spinal cord. Histochemistry $76: 33-49$. 